\title{
SKUTECZNOŚĆ PROGNOZOWANIA ZUŻYCIA GAZU Z WYKORZYSTANIEM METOD REGRESJI I SZTUCZNYCH SIECI NEURONOWYCH
}

\begin{abstract}
Na podstawie zgromadzonych danych takich jak: temperatura, siła wiatru oraz zużycie gazu w ciągu dnia na przestrzeni dwóch lat określono wpływ czynników atmosferycznych na konsumpcje gazu za pomocą regresji wielorakiej, funkcji potęgowych oraz funkcji użytkownika. Wyznaczono wpływ miesiąca oraz dnia (parametr sztuczny) na konsumpcje gazu. Zbudowano modele regresji liniowe, potęgowej oraz sztuczne sieci neuronowe służące do określania zużycia gazu. Starano się wyznaczyć jak najlepszy model regresji i porównywano go do modeli sieci neuronowych za pomocą MAPE (średni absolutny błąd procentowy).
\end{abstract}

Słowa kluczowe: regresja liniowa, regresja potęgowa, parametry sztuczne, sztuczne sieci neuronowe, konsumpcja gazu

\section{Wstęp}

Prognozowanie pracy sieci gazowej, ilości magazynowanego i konsumowanego gazu jest istotna $\mathrm{w} w$ procesie zrównoważonego rozwoju. Prognozowanie zapewnia odpowiednie planowanie modernizacji sieci gazowych ponieważ można przewidzieć w jakim okresie będzie największy pobór czyli obciążenie sieci i tłoczni. Podejmowanie decyzji związane z rozwojem systemu dystrybucji staje się łatwiejsze i szybsze ze względu na posiadane informację o wielkości zużycia w przyszłości. Dzięki informacją uzyskanym podczas analiz można w łatwy sposób przewidzieć ilość potrzebnego gazu oraz zarządzać system magazynów gazu co jest istotne z punktu widzenia bezpieczeństwa energetycznego kraju.

\footnotetext{
1 Autor do korespondencji / corresponding author: Tomasz Cieślik, Instytut Fizyki Jądrowej PAN Aleja Radzikowskiego 152, 31-342 Kraków oraz AGH Akademia Górniczo- Hutnicza, Aleja Adama Mickiewicza 30, 30-059 Kraków, email: tomasz.cieslik@ifj.edu.pl

2 Klaudia Metelska, AGH Akademia Górniczo- Hutnicza, Wydział Wiertnictwa, Nafty i Gazu, Aleja Adama Mickiewicza 30, 30-059 Kraków
} 


\section{Prognozowanie zużycia gazu}

Celem pracy jest prognozowanie zużycia gazu dla 1 miesiąca na podstawie zgromadzonych danych z 23 miesięcy takich jak: pobór gazu, temperatura otoczenia i siła wiatru. Do prognozowania zużycia gazu wykorzystane zostaną zmienne sztuczne takie jak dzień tygodnia oraz miesiąc. Obliczenia zostały wykonane na programach: Statystica i Gretl.

Można zauważyć iż konsumpcja jest silnie zależna od temperatury. W zimie kiedy spada temperatura to następuje wzrost konsumpcji gazu (rys. 1).

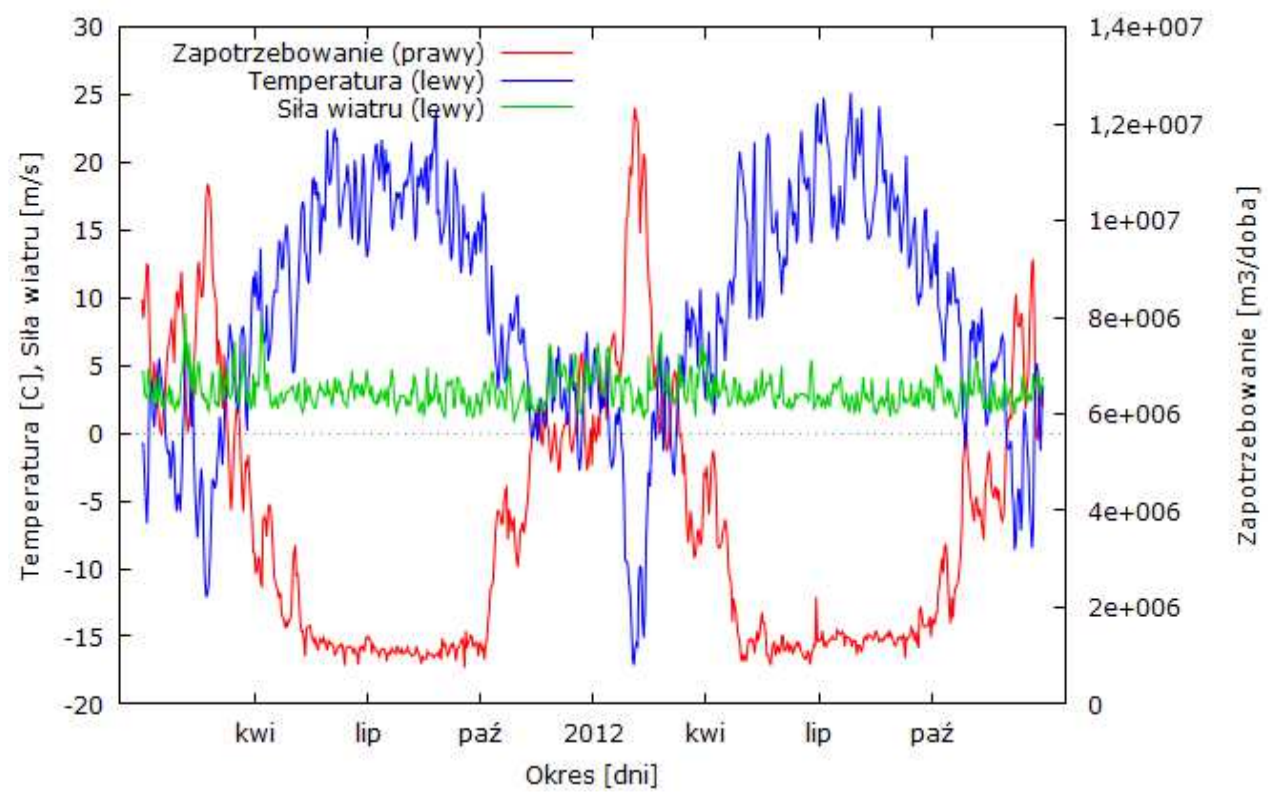

Rys. 1. Zużycie gazu w przeciągu dwóch lat w zależności od temperatury i siły wiatru.

Fig. 1. Gas consumption within two years depending on the temperature and wind strength.

\subsection{Metody regresji}

Regresja to metoda statystyczna polegająca na badaniu związków pomiędzy danymi i przewidywaniu na tej podstawie nieznanych wartości przy pomocy innych wartości[1].

Założenia[1-4]:

- Postać modelu jest liniowa- $\mathrm{Y}=\beta \mathrm{x}+\varepsilon$

gdzie:

$\beta$ - parametr

$\varepsilon$ - zdarzenie losowa 
- Macierz x jest znana i nie jest losowa

Rzad $\mathrm{x}=\mathrm{k}$ k- liczba parametrów

$\mathrm{T}>\mathrm{k}$

gdzie:

k- liczba parametrów

T- liczba obserwacji

Gdy rząd macierzy $X$ nie jest $k$, to wówczas det $\left(\mathrm{x}^{\mathrm{T}} \mathrm{x}\right)=0$ i nie istnieje macierz odwrotna, czyli nie da się oszacować parametrów.

- Wartość oczekiwana składnika losowego równa się zero

- Wariancja składnia losowego jest stała i równa się $\sigma^{2}$

\subsubsection{Regresja liniowa}

Model liniowy ma następująca wzór ogólny(1)[1-4]: Postać:

$$
\mathrm{Y}=\beta_{0}+\beta_{1} * \mathrm{X}_{1}+\beta_{2} * \mathrm{X}_{2}+\ldots+\beta_{\mathrm{k}} * \mathrm{X}_{\mathrm{k}}+\varepsilon
$$

gdzie:

Y- zmienna badana (której wartość jest objaśniana przez model - endogeniczna)

$\mathrm{X}_{1} \ldots \mathrm{X}_{\mathrm{k}}$ - zmienne za pomocą których badamy $\mathrm{Y}$

$\beta_{0}, \beta_{1}, \beta_{2} \ldots \beta_{k}$ - parametry modelu (liczby) $\varepsilon$ - składnik losowy

W modelu liniowym regresji badano wpływ temperatury i siły wiatru na konsumpcje gazu (Tabela 1) a następnie wykorzystano parametry sztuczne (Tabela 2) takie jak miesiąc i dzień w celu poprawy jakości modelu.

Tabela 1. Podsumowanie regresji liniowej bez parametrów sztucznych.

Table 1. Summary linear regression without artificial parameters.

\begin{tabular}{|c|c|c|c|c|c|c|}
\hline \multirow[b]{2}{*}{$\mathrm{N}=700$} & \multicolumn{6}{|c|}{$\begin{array}{l}\text { Podsumowanie regresji zmiennej zależnej: Zapotrzebowanie } \mathrm{m}^{3} \mathrm{R}=, 945 \mathrm{R}^{2}=, 892 \text { Popraw. } \\
\mathrm{R}^{2}=, 892 \\
\mathrm{~F}(2,697)=2874,3 \mathrm{p}<0,0000 \text { Błąd std. estymacji: } 8795 \mathrm{E} 2\end{array}$} \\
\hline & $\mathrm{b}^{*}$ & Bł. std. & $\mathrm{b}$ & Bł. std. & $\mathrm{t}(697)$ & $\mathrm{p}$ \\
\hline W. wolny & & & 6048820 & 106724,9 & 56,6768 & 0,000000 \\
\hline Temperatura [st. C] & $-0,937984$ & 0,012603 & -296427 & 3982,7 & $-74,4283$ & 0,000000 \\
\hline Siła wiatru $[\mathrm{m} / \mathrm{s}]$ & 0,037325 & 0,012603 & 85557 & 28887,4 & 2,9617 & 0,003163 \\
\hline
\end{tabular}

Ocena szacowania parametrów dla regresji liniowej bez parametrów sztucznych:

- $\quad$ Standardowy błąd estymacji $=879500$

- Rzeczywiste wartości Y różnią się od teoretycznych przeciętnie o 879500 co stanowi $23 \%$ średniego Y.

- $\quad \mathrm{R}^{\wedge} 2=0,89$ - wokoło 89,18\% całkowitej zmienność Y została wyjaśniona przez oszacowany model. 
Model przyjmuje postać:

$\mathrm{Y}=6048820-296427 * \mathrm{X}_{1}+85557 * \mathrm{X}_{2}$

gdzie:

$\mathrm{X}_{1}$ - temperatura $[\mathrm{C}]$

$\mathrm{X}_{2}$ - siła wiatru $[\mathrm{m} / \mathrm{s}]$

Tabela 2. Podsumowanie regresji liniowej bez parametrów sztucznych.

Table 2. Summary linear regression without artificial parameters.

\begin{tabular}{|c|c|c|c|c|c|c|}
\hline \multirow[b]{2}{*}{$\mathrm{N}=700$} & \multicolumn{6}{|c|}{$\begin{array}{l}\text { Podsumowanie regresji zmiennej zależnej: Zapotrzebowanie } \mathrm{m}^{3} \\
\mathrm{R}=, 969 \mathrm{R}^{2}=, 939 \text { Popraw. } \mathrm{R}^{2}=, 939 \\
\mathrm{~F}(8,691)=1336,1 \mathrm{p}<0,0000 \text { Błąd std. estymacji: } 6619 \mathrm{E} 2\end{array}$} \\
\hline & $\mathrm{b}^{*}$ & Bł. std. & $\mathrm{b}$ & Bł. std. & $\mathrm{t}(691)$ & $\mathrm{p}$ \\
\hline W. wolny & & & 5340757 & 78950,8 & 67,6467 & 0,000000 \\
\hline Temperatura [st. C] & $-0,778101$ & 0,016764 & -245900 & 5298,0 & $-46,4138$ & 0,000000 \\
\hline Styczeń & 0,192992 & 0,012420 & 1812827 & 116665,4 & 15,5387 & 0,000000 \\
\hline Luty & 0,218133 & 0,013633 & 2128631 & 133040,8 & 15,9998 & 0,000000 \\
\hline Marzec & 0,091487 & 0,011082 & 859359 & 104094,1 & 8,2556 & 0,000000 \\
\hline Lipiec & 0,057332 & 0,010480 & 538535 & 98445,0 & 5,4704 & 0,000000 \\
\hline Sierpień & 0,044398 & 0,010434 & 417045 & 98005,9 & 4,2553 & 0,000024 \\
\hline Październik & $-0,036217$ & 0,010204 & -340199 & 95849,4 & $-3,5493$ & 0,000412 \\
\hline Listopad & 0,037033 & 0,010957 & 353054 & 104464,1 & 3,3797 & 0,000767 \\
\hline
\end{tabular}

Ocena szacowania parametrów dla regresji liniowejz parametrami sztucznymi:

- $\quad$ Standardowy błąd estymacji $=661900$

- Rzeczywiste wartości Y różnią się od teoretycznych przeciętnie o 661900 co stanowi $18 \%$ średniego Y.

- $\quad \mathrm{R}^{\wedge} 2=0,93$ - wokoło 93,92\% całkowitej zmienność Y została wyjaśniona przez oszacowany model.

Model przyjmuje postać:

$\mathrm{Y}=5340757-245900 * \mathrm{X}_{1}+\mathrm{M} * \mathrm{X}_{2}$

gdzie:

$\mathrm{X}_{1}$ - temperatura $[\mathrm{C}]$

$\mathrm{MX}_{2}$ - dany miesiąc dla którego jest wykonywana prognoza.

\subsubsection{Regresja potęgowa}

Model potęgowy ma następująca wzór ogólny[1-4]:

$$
\mathrm{Y}=\beta_{0} * \mathrm{X}_{1}^{\beta_{1}} * \mathrm{X}_{2}^{\beta_{2}} * \ldots * \mathrm{X}_{\mathrm{k}}^{\beta_{\mathrm{k}}}
$$

gdzie:

Y- zmienna badana (której wartość jest objaśniana przez model - endogeniczna)

$\mathrm{X}_{1} \ldots \mathrm{X}_{\mathrm{k}}$ - zmienne za pomocą których badamy $\mathrm{Y}$

$\beta_{0}, \beta_{1}, \beta_{2} \ldots \beta_{k}$ - parametry modelu (liczby)

$\varepsilon$ - składnik losowy 
Sprowadzamy do postaci liniowej przez logarytmowanie $\ln (4)$

$$
\begin{aligned}
& \ln (Y)=\ln \left(\beta_{0} * X_{1}^{\beta_{1}} * X_{2}^{\beta_{2}} * \ldots * X_{k}^{\beta_{k}}\right) \\
& \ln (Y)=\ln \beta_{0}+\beta_{1} \ln X_{1}+\beta_{2} \ln X_{2}+\cdots+\beta_{k} \ln X_{k} \\
& \ln (Y)=Y^{\prime} \\
& \ln X_{1}=X^{\prime} \\
& Y^{\prime}=\beta_{0}+\beta_{1} * X_{1}^{\prime}+\beta_{2} * X_{2}^{\prime}+\ldots+\beta_{k} * X_{k}^{\prime}
\end{aligned}
$$

W modelu potęgowym badano wpływ temperatury i siły wiatru na kon-

\begin{tabular}{|c|c|c|c|c|c|c|}
\hline \multirow[b]{2}{*}{$\mathrm{N}=700$} & \multicolumn{6}{|c|}{$\begin{array}{l}\text { Podsumowanie regresji zmiennej zależnej: Ln (Zaopatrzenie[m3]) } \\
R=, 939 \mathrm{R}^{2}=, 8808 \text { Popraw. } \mathrm{R}^{2}=, 8805 \\
\mathrm{~F}(2,697)=2574,7 \mathrm{p}<0,0000 \text { Bład std. estymacji: }, 26750\end{array}$} \\
\hline & $\mathrm{b}^{*}$ & Bł. std. & $\mathrm{b}$ & Bł. std. & $\mathrm{t}(697)$ & $\mathrm{p}$ \\
\hline W. wolny & & & 148,2051 & 1,909542 & 77,6129 & 0,000000 \\
\hline $\ln ($ Temp. [st. K]) & $-0,923599$ & 0,013173 & $-23,6798$ & 0,337729 & $-70,1150$ & 0,000000 \\
\hline $\ln ($ wiatr $[\mathrm{m} / \mathrm{s}])$ & 0,089524 & 0,013173 & 0,1896 & 0,027893 & 6,7962 & 0,000000 \\
\hline
\end{tabular}
sumpcje gazu (Tabela 3) a następnie wykorzystano parametry sztuczne (Tabela 4) takie jak miesiąc i dzień w celu poprawy jakości modelu.

Tabela 3. Podsumowanie regresji potęgowej bez parametrów sztucznych Table 3. Summary of the power regression without artificial parameters

Ocena szacowania parametrów dla regresji potęgowej bez parametrów sztucznych

-Standardowy błąd estymacji $=0,26750$.

- Rzeczywiste zlogarytmowane Y różnią się od teoretycznych zlogarytmowanych o 0,24 , co stanowi 1,8 \% średniego zlogarytmowanego Y.

$-\mathrm{R}^{\wedge} 2=0,88$ - wokoło $88 \%$ całkowitej zmienność zlogarytmowanego Y została wyjaśniona przez oszacowany model.

Model przyjmuje postać:

$\ln (\mathrm{Y})=148,2051-23,6789 \ln \mathrm{X}_{1}+0,1896 \ln \mathrm{X}_{2}$

gdzie:

$\mathrm{X}_{1}$ - temperatura $[\mathrm{K}]$

$\mathrm{X}_{2}$ - siła wiatru $[\mathrm{m} / \mathrm{s}]$

Ocena szacowania parametrów dla regresji potęgowej z zmienymi sztucznymi (Tabela 4):

- Standardowy błąd estymacji $=0,17812$;

- Rzeczywiste zlogarytmowane Y różnią się od teoretycznych zlogarytmowanych o 0,17 co stanowi $1,2 \%$ średniego zlogarytmowanego $\mathrm{Y}$;

- $\mathrm{R}^{\wedge} 2=0,94$ - wokoło 94\% całkowitej zmienność zlogarytmowanego Y została wyjaśniona przez oszacowany model. 
Model przyjmuje postać:

$\ln (\mathrm{Y})=87,3700-12,9399 \ln \mathrm{X}_{1}+\mathrm{MX}_{2}$

gdzie:

$\mathrm{X}_{1}$ - temperatura $[\mathrm{K}]$

$\mathrm{MX}_{2}$ - dany miesiąc dla którego jest wykonywana prognoz

Tabela 4. Podsumowanie regresji potęgowej z parametrami sztucznymi

Table 4. Summary of the power regression with artificial parameters

\begin{tabular}{|c|c|c|c|c|c|c|}
\hline \multirow[b]{2}{*}{$N=700$} & \multicolumn{6}{|c|}{$\begin{array}{l}\text { Podsumowanie regresji zmiennej zależnej: } \mathrm{Ln}(\text { Zaopatrzenie[m3]) } \\
\mathrm{R}=, 974 \mathrm{R}^{2}=, 948 \text { Popraw. } \mathrm{R}^{2}=, 947 \\
\mathrm{~F}(9,690)=1388,4 \mathrm{p}<0,0000 \text { Błąd std. estymacji: }, 17812\end{array}$} \\
\hline & $\mathrm{b}^{*}$ & Bł. std. & $\mathrm{b}$ & Bł. std. & $\mathrm{t}(690)$ & $\mathrm{p}$ \\
\hline W. wolny & & & 87,3700 & 2,670057 & 32,7221 & 0,000000 \\
\hline $\ln ($ Temp. [stp. K]) & $-0,504704$ & 0,018375 & $\begin{array}{ll}-12,9399 \\
\end{array}$ & 0,471120 & $-27,4663$ & 0,000000 \\
\hline Styczeń & 0,359376 & 0,013902 & 0,9778 & 0,037825 & 25,8510 & 0,000000 \\
\hline Luty & 0,330110 & 0,015531 & 0,9331 & 0,043901 & 21,2547 & 0,000000 \\
\hline Marzec & 0,307551 & 0,011951 & 0,8368 & 0,032518 & 25,7340 & 0,000000 \\
\hline Kwiecień & 0,190109 & 0,010059 & 0,5250 & 0,027777 & 18,9002 & 0,000000 \\
\hline Lipiec & 0,037802 & 0,009436 & 0,1029 & 0,025673 & 4,0063 & 0,000068 \\
\hline Październik & 0,147741 & 0,010433 & 0,4020 & 0,028386 & 14,1612 & 0,000000 \\
\hline Listopad & 0,271417 & 0,011741 & 0,7495 & 0,032423 & 23,1171 & 0,000000 \\
\hline Grudzień & 0,238392 & 0,010833 & 0,8958 & 0,040708 & 22,0055 & 0,000000 \\
\hline
\end{tabular}

\subsection{Sztuczne sieci neuronowe}

W skład sztucznej sieci neuronowej wchodzi sztuczny neuron czyli podstawowy element budujący sztuczną sieć neuronową (Rysunek 2). Jest on "przetwornikiem" który na wejściu przyjmuje sygnały wejściowe i mnoży je poprzez odpowiednie wartości wag w zależności od istotności danego sygnału na wartość wyjściową. Sygnały po przemnożeniu przez wagi są sumowane i korygowane w bloku sumującym. Służy to do wyznaczania pobudzenia neuronu. Sygnały pobudzone kierowane są do nie liniowej funkcji aktywacji w celu wygenerowania na wyjściu odpowiedniego sygnału [5].

Uczenie sieci neuronowych jest wtedy stosowane gdy nie mamy informacji na temat powiazań występujących pomiędzy wszystkimi wejściami a wyjściami. Uczenie polega na dobieraniu wag przy których sieć da najlepsze rozwiązanie. Wyróżnia się uczenie z nauczyciele oraz bez nauczyciela.

Uczenie z nauczycielem polega na podawaniu wzorcowych sygnałów na wejściu I oczekiwanych sygnałów na wyjściu. Sieć dobiera sobie automatycznie wagi w celu nauczenia się funkcji opisującej powiazania sygnałów wejściowych z sygnałem wyjściowym. Uczenie bez nauczyciela polega na odbieraniu sygnałów na wejściu i na tej podstawie wyznaczania wyjścia. Proces ten odbywa się bez wag wzorcowych. [5,7-13] 


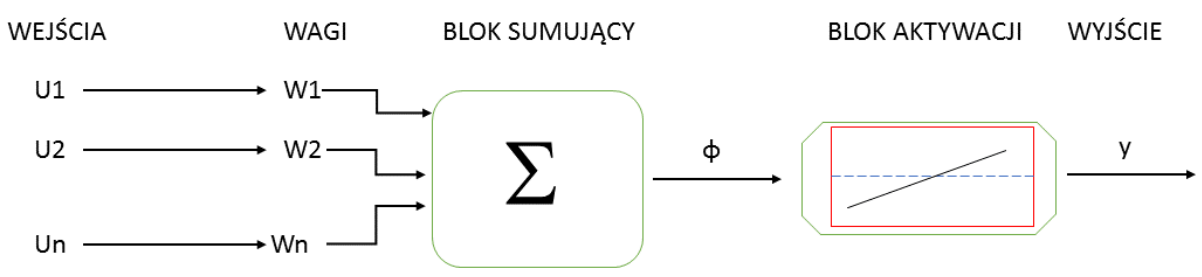

Rys. 2. Modle sztucznego neuronu (Na podstawie [6])

Fig. 2. Model of artificial neuron. (According to [6] )

gdzie:

u $\mathrm{u}_{\mathrm{i}}$-wejścia - to dendryty, lub ściślej sygnały przez nie dchodzące,

$\mathrm{w}_{\mathrm{i}}$-wagi - są odpowiednikami synaps,

$\Sigma$-blok sumacyjny - odpowiednik jądra,

$\mathrm{f}(\Sigma)$-blok aktywacji - to odpowiednik wzgórka aksonu,

y-wyjście - to odpowiednik aksonu

\section{Parametry uczenia}

$\mathrm{Na}$ podstawie parametrów (Tabela 5) przeprowadzono uczenie dla sztucznej sieci neuronowej bez parametrów sztucznych i uzyskano $\mathrm{R}^{\wedge} 2=0,982$ a dla sztucznej sieci neuronowej z parametrami sztucznymi $R^{\wedge} 2=0,984$.

Tabela 5. Parametry symulacji

Table 5. Simulation parameters

\begin{tabular}{|c|c|}
\hline Nazwa parametru & Wartość \\
\hline Liczba warstw ukrytych & 3 \\
\hline Funkcja błędów & Suma kwadratów \\
\hline Funkcje aktywacji - neurony ukryte & wykładnicza, logistyczna \\
\hline Funkcja aktywacji- neurony wyjściowe & wykładnicza, logistyczna \\
\hline Redukcja wag- warstwy ukrytej & Min.-0,0001, maks.-0,001 \\
\hline Redukcja wag- warstwy wyjściowej & Min.-0,0001, maks.-0,001 \\
\hline
\end{tabular}

\subsection{Wyniki}

Na podstawie uzyskanych wyników dla regresji (Tabela 1-4) i z wykorzystaniem nauczonej sieci neuronowej według ustalonych parametrów (Tabela 5) przeprowadzamy prognozę dla 1 miesiąca (Rysunek 3). 


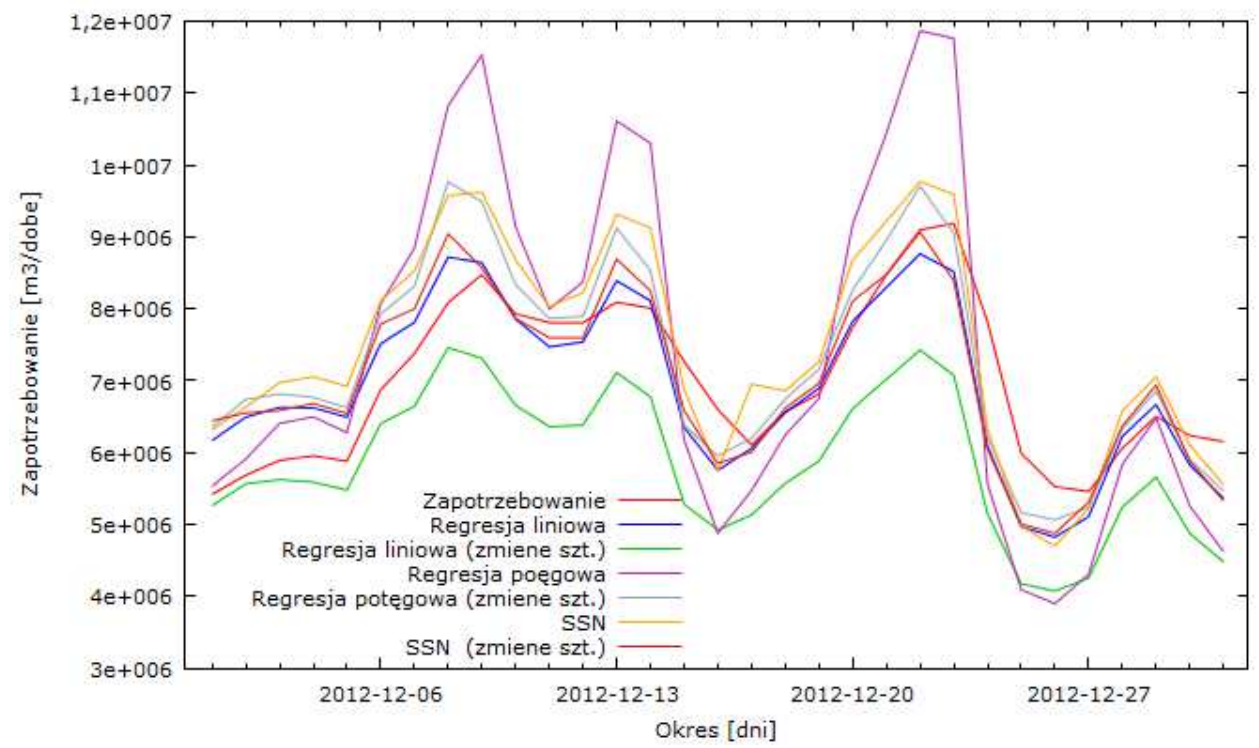

Rysunek 3 Prognoza komsupcji gazu z wykorzystaniem wszystkich metod.

Figure 3 Forecast gas consumption using all metods

\section{Wnioski}

Błąd MPAE (średni absolutny błąd procentowy ) był najmniejszy dla regresji liniowej w przypadku nie wykorzystywania zmiennych sztucznych i wyniósł (tabela 6). $\mathrm{Z}$ kolei dla regresji potęgowej wynosił on $16,1 \%$ a dla sieci neuronowych $10,7 \%$. Dodanie zmiennych sztucznych pogorszyło jakość modelu w przypadku regresji liniowej do wartości $17,1 \%$ natomiast poprawiło w przypadku regresji potęgowej i sztucznych sieci neuronowych. Wśród wszystkich modeli najlepszym okazywało się sztuczne sieci neuronowe z zmiennymi sztucznymi. Podczas zmiennych sztucznych okazało się ze w przypadku regresji liniowej jak i potęgowej tygodnia nie są istotne jak również silą wiatru oraz niektóre miesiące.

Tabela 6. Porowananie modeli

Table 6. Comparison modles

\begin{tabular}{|c|c|c|c|c|c|c|}
\hline & \multicolumn{2}{|c|}{ Regresja Liniowa } & \multicolumn{2}{c|}{ Regresja Potęgowa } & \multicolumn{2}{c|}{ SSN } \\
\hline Parametr & $\begin{array}{c}\text { Bez zmiennych } \\
\text { sztucznych }\end{array}$ & $\begin{array}{c}\text { Z zmiennymi } \\
\text { sztucznymi. }\end{array}$ & $\begin{array}{c}\text { Bez zmien- } \\
\text { nych sztucz- } \\
\text { nych }\end{array}$ & $\begin{array}{c}\text { Z zmiennymi } \\
\text { sztucznymi. }\end{array}$ & $\begin{array}{c}\text { Bez } \\
\text { zmiennych } \\
\text { sztucznych }\end{array}$ & $\begin{array}{c}\text { Z zmiennymi } \\
\text { sztucznymi. }\end{array}$ \\
\hline $\begin{array}{c}\text { MAPE } \\
{[\%]}\end{array}$ & 7,89 & 17,1 & $16,1 \%$ & 9.61 & 10,6 & 7,28 \\
\hline
\end{tabular}




\section{Literatura}

[1] Koronacki J., Ćwik J.: Statystyczne systemy uczące się, Wydawnictwa NaukowoTechniczne, Warszawa 2005.

[2] Rabiel M.: Statystyka z programem Statystica, Wydawnictwo Helion, Gliwice 2012.

[3] Stanisz A; Przystępny kurs statystyki zastosowaniem programu Statystica na przykładach z medycyny, Tom II, Wydawnictwo StatSoft Polska, Kraków 2006.

[4] Goryl A: Wprowadzenie do ekonometrii w przykładach i zadaniach, PWN, 2000.

[5] Żurada J., Barski M., Jędruch W.: „Sztuczne sieci neuronowe”, Wydawnictwo Naukowe PWN, Warszawa 1996.

[6] http://galaxy.uci.agh.edu.pl/ vlsi/AI/wstep/ data dostępu: 27.06.2016, godzina 09:00.

[7] Tadeusiewicz R.: Sieci neuronowe, Państwowa Oficyna Wydawnicza RM, Warszawa 1993.

[8] Tadeusiewicz R.: Elementarne wprowadzenie do technik sieci neuronowych z przykładowymi programami, Warszawa 1998.

[9] Stefanowski J., Krawiec K.: Wykłady sieci neuronowych, 1995.

[10] Wójcik M.: Model sieci gazowniczej oparty o sztuczne sieci neuronowe, AGH, Kraków 2005.

[11] Kogut K.: Analiza możliwości modelowani sieci przesyłowej gazu ziemnego. AGH, Kraków 2007.

[12] Maciejasz M.: Zastosowanie sieci neuronowy do analizy pracy sieci przesyłowych, AGH, Kraków 2006.

[13] Praca zbiorowa pod redakcją Rymarczyka M.: Decyzje, Symulacje, Sieci Neuronowe, Wydawnictwo Wyższej Szkoły Bankowej w Poznaniu 1997.

\section{PREDICTION OF GAS CONSUMPTION EFFICIENCY USING REGRESSION AND ARTIFICIAL NEURAL NETWORKS}

\section{S u m m a r y}

Based on the collected data, such as temperature, wind power and gas consumption during the day for over two years determine the effects of weathering on gas consumption by using multiple regression, power functions and user functions. We determine the impact of the month and day (artificial parameter) to consume gas. We build models of linear regression-in, power series and artificial neural networks for determining gas consumption. We are trying to determine how best regression model and compare it to the neural network models using MAPE (mean absolute percentage error).

Keywords: linear regression, exponential regression, the parameters of artificial neural networks, gas consumption

Przestano do redakcji: 08.03.2017 r.

Przyjęto do druku: 31.03.2017 r. 